\title{
PERHITUNGAN PRODUKTIVITAS BULLDOZER PADA AKTIVITAS DOZING DI PT. PAMAPERSADA NUSANTARA TABALONG KALIMANTAN SELATAN
}

\author{
Hj. Rezky Anisari \\ rezky_anisari@poliban.ac.id \\ Staf Pengajar Jurusan Teknik Sipil Politeknik Negeri Banjarmasin
}

\begin{abstract}
Ringkasan
Kegiatan produksi penambangan di PT. Pamapersada Nusantara diawali dengan pengupasan tanah penutup (overburden). Tanah penutup merupakan lapisan tanah yang berada menutupi lapisan bahan galian sehingga harus terlebih dahulu diangkat agar bahan galian yang diinginkan dapat mudah untuk diangkat. Dalam kegiatannya material overburden diangkut menuju area disposal untuk ditimbun dengan cara digusur menggunakan alat support bulldozer. Disposal merupakan daerah pada suatu operasi tambang terbuka yang digunakan sebagai tempat membuang material tanah penutup. Sebagai upaya mengontrol laju produksi pengisian disposal serta memenuhi plan desain kemajuan disposal, salah satunya yaitu keberhasilan kegiatan penggusuran material overburden dengan memperhitungkan seberapa besar produktivitas aktual peralatan mekanis bulldozer dapat dimanfaatkan seefektif mungkin dalam melakukan pekerjaannya.

Metode yang digunakan pada penelitian ini adalah dengan mengamati secara langsung, diskusi serta studi literature. Objek penelitian dilakukan yaitu alat gusur Bulldozer D155A Komatsu pada area disposal highwall PT. Pamapersada Nusantara.

Berdasarkan hasil perhitungan maka didapat produktivitas alat gusur Bulldozer D155A pada tanggal 07 Maret 2017 jam 14:15-15:15 adalah 838,16 Bcm/jam dengan ketercapaian target 69\%, dan tanggal 08 Maret 2017 jam 08:30-09:30 adalah 889,60 Bcm/jam dengan ketercapaian target $74 \%$.
\end{abstract}

Kata kunci: Disposal, Produktivitas, Bulldozer.

\section{A. PENDAHULUAN \\ Latar Belakang \\ Disposal merupakan daerah pada suatu} operasi tambang terbuka yang digunakan sebagai tempat membuang material tanah penutup Kebutuhan akan sumber daya potensial batubara sebagai sumber energi bagi perindustrian di Indonesia kian hari semakin meningkat. Hal ini didasarkan pada peningkatan jumlah penduduk di Indonesia. Sebaran cekungan batubara terhampar luas di sepanjang daratan Indonesia, khususnya di pulau Kalimantan. Dalam perkembangan perindustrian, kebutuhan akan sumber daya energi batubara semakin meningkat, dampaknya cadangan pun semakin menipis dan perlu diingat batubara merupakan sumber daya alam yang tidak dapat diperbaharui.

Di pulau Kalimantan khususnya Kalimantan Selatan, perusahaan batubara tersebar dibeberapa daerah salah satunya di PT. Pamapersada Nusantara Jobsite PT. Adaro Indonesia Kabupaten Tabalong. Kegiatan produksi penambangan di PT. Pamapersada Nusantara diawali dengan pengupasan tanah penutup (overburden). Tanah penutup merupakan lapisan tanah yang berada menutupi lapisan bahan galian sehingga harus terlebih dahulu diangkat agar bahan galian yang diinginkan dapat mudah untuk diangkat. Dalam kegiatannya material overburden diangkut menuju area disposal untuk ditimbun dengan cara digusur menggunakan alat support bulldozer.

Disposal merupakan daerah pada suatu operasi tambang terbuka yang digunakan sebagai tempat membuang material tanah penutup. Sebagai upaya mengontrol laju produksi pengisian disposal serta memenuhi plan desain kemajuan disposal, salah satunya yaitu keberhasilan kegiatan penggusuran material overburden dengan memperhitungkan seberapa besar produktivitas aktual peralatan mekanis bulldozer dapat dimanfaatkan seefektif mungkin dalam melakukan pekerjaannya. Oleh karena itu, kajian ini ditekankan pada kajian teknis perhitungan produktivitas aktual alat support bulldozer D155A berdasarkan kapasitas blade, waktu siklus (cycle time), dan efisiensi kerja pada aktivitas dozing di disposal. 


\section{Alat Gusur}

Alat gusur adalah alat yang mengubah energi mesin menjadi energi mekanik, bentuk nyata dari energi mekanik adalah berupa gaya dorong (dozing), namun apabila energi mekanik berupa tarikan oleh gaya tarik maka disebut alat tarik (tractor), dan tractor yang dilengkapi alat gusur (blade) disebut bulldozer. Dengan demikian tractor merupakan penggerak utama (prime mover) untuk bulldozer.

Pada dasarnya bulldozer adalah alat mekanis yang menggunakan tractor sebagai penggerak utama (prime mover) yang dilengkapi dengan dozer attachment. Bentuk attachmentnya yaitu blade. Bulldozer dirancang sebagai alat berat yang diberi kemampuan untuk mendorong ke depan. (Indonesianto, 15).

\section{Macam-macam Bulldozer}

Menurut Indonesianto (2015), Macam bulldozer berdasarkan pada:

\section{Undercarriage}

Undercarriage adalah bagian-bagian bulldozer yang berada dibawah cabin, yang berfungsi untuk menggerakkan bulldozer ke depan atau ke belakang. Roda penggeraknya bisa roda rantai disebut crawler atau bisa pula roda ban disebut tires atau wheel.

\section{Attachment}

Macam bulldozer berdasarkan attachment nya (kelengkapan mekanis) yang dipasang pada bagian depan disebut blade atau rake, bila berupa garpu, sedang yang dipasang dibagian belakang disebut ripper.

\section{Media/alat penggerak blade}

Berdasarkan media penggerak blade nya terdiri dari bulldozer dengan penggerak hydraulic dan bulldozer dengan penggerak kabel.

\section{Waktu Siklus (cycle time)}

Setiap alat berat yang bekerja akan mempunyai kemampuan memindah material persiklus. Siklus kerja adalah proses gerakan dari suatu alat dari gerakan mulanya sampai kembali lagi pada gerakan mula tersebut. Adapun waktu yang diperlukan untuk melakukan satu siklus kegiatan diatas disebut dengan waktu siklus edar.

Dalam pemindahan material, siklus kerja merupakan suatu kegiatan oleh alat yang dilakukan berulang. Pekerjaan utama dalam melakukan kegiatan untuk melakukan satu siklus kerja. Dalam operasi alat berat produksi dilapangan, umumnya semua berjalan pada sebuah siklus. Komponen-komponen waktu siklus untuk alat gusur bulldozer tersebut adalah:

Cycle time $=$ dozing + reversing + gear shifting

Keterangan:

Dozing = Waktu mendorong material

Reversing = Waktu kembali mundur

Gear shifting = Waktu ganti perseneling

(Sumber : Specification and Application Handbook (Komatsu), edition 30)

\section{Faktor yang Mempengaruhi Waktu Siklus Bulldozer} yaitu:

Faktor yang mempengaruhi waktu siklus

1. Ukuran Unit

Semakin besar unit, cycle timenya semakin lambat,

2. Jenis material

Terdapatnya bongkahan material overburden besar dan jenis material basah seperti material cut back dan spoil maka mengakibatkan daya dorong terhadap material tinggi dan berpengaruh pada lamanya waktu penggusuran,

3. Keterampilan Operator

Semakin bagus keterampilan operator dalam mengoperasikan unit, maka cycle time akan cepat. (PT. Pamapersada Nusantara)

(Sumber : Specification and Application Handbook (Komatsu), edition 30)

Upaya untuk mengontrol laju produksi pengisian disposal serta memenuhi plan desain kemajuan disposal, salah satunya yaitu keberhasilan kegiatan penggusuran material overburden dengan memperhitungkan seberapa besar produktivitas aktual peralatan mekanis bulldozer dapat dimanfaatkan seefektif mungkin dalam melakukan pekerjaannya. Oleh karena itu, kajian ini ditekankan pada kajian teknis perhitungan produktivitas aktual alat support bulldozer D155A berdasarkan kapasitas blade, waktu siklus (cycle time), dan efisiensi kerja pada aktivitas dozing di disposal.

\section{Perumusan Masalah}

1. Berapa produktivitas bulldozer D155A pada aktivitas dozing di disposal,

2. Ketercapaian produktivitas terhadap material overburden yang masuk.

\section{Tujuan}

Untuk mengetahui waktu siklus (cycle time) alat support bulldozer, dan untuk mengetahui produktivitas bulldozer D155A 


\section{Manfaat}

Mampu menghitung produktivitas alat support bulldozer secara actual.

\section{B. LANDASAN TEORI}

\section{Alat Gusur}

Pada dasarnya bulldozer adalah alat mekanis yang menggunakan tractor sebagai penggerak utama (prime mover) yang dilengkapi dengan dozer attachment. Bentuk attachmentnya yaitu blade. Bulldozer dirancang sebagai alat berat yang diberi kemampuan untuk mendorong ke depan. (Indonesianto,15)

\section{Waktu Siklus (cycle time)}

Adapun waktu yang diperlukan untuk melakukan satu siklus kegiatan diatas disebut dengan waktu siklus edar.

\section{Cycle time $=$ dozing + reversing + gear shifting $\quad \ldots 2.1$}

\section{Keterangan:}

Dozing
Reversing = Waktu mendorong material
Gear shifting = Waktu kembali mundur
(Sumber: Specification ganti perseneling
Handbook (Komatsu), edition 30) Application

Faktor yang Mempengaruhi Produktivitas Dozer

1. Ukuran Blade (Blade capacity)

Semakin besar ukuran blade maka volume yang terdorong setiap cycle time akan semakin besar

2. Faktor Pengembang (Swell Factor)

Cara yang sangat umum dipakai untuk menentukan efisiensi alat adalah dengan menghitung berapa menit alat tersebut berjeda secara efektif dalam satu jam, diformulasikan sebagai berikut:

\section{$E=C T /(C T+D T) \times 100 \% \ldots 2.2$}

Keterangan:

$$
\begin{array}{ll}
\mathrm{E} & =\text { Efisiensi } \\
\mathrm{CT} & =\text { Cycle Time } \\
\mathrm{DT} & =\text { Delay Time }
\end{array}
$$

(Sumber : Susy Fatena Rostiyanti, 2008)

\section{Produktivitas Alat Gusur}

Produktivitas adalah hasil dari proses produksi dalam satuan bcm/jam, yang dapat diperoleh dari:

\section{$Q=q \times 60$ menit $/ \mathrm{Cm} \times \mathrm{e} \times \mathrm{E} \quad \ldots 2.3$}

Keterangan:

$$
\mathbf{Q} \quad=\text { Produksi (BCM/jam) }
$$

\author{
q= Kapasitas blade $\times$ Faktor blade \\ $\mathrm{Cm} \quad=$ Cycle time \\ e = Faktor kelandaian (grade factor) \\ E = Efesiensi kerja \\ (Sumber : Specification and Application \\ Handbook (Komatsu), edition 30)

\section{METODE PENELITIAN}

\section{Kondisi Umum Perusahaan}

Kondisi umum perusahaan menjelaskan tentang keadaan umum perusahaan sebagai tempat dilakukannya penelitian dengan Sistem penambangan di PT. Pamapersada Nusantara jobsite PT. Adaro Indonesia merupakan sistem penambangan Tambang Terbuka dengan menggunakan metode open pit. Material overburden dimuat, diangkut, dan kemudian ditimbun di beberapa lokasi di luar pit (disposal). Tahapan kegiatan penambangan pada PT. Pamapersada Nusantara adalah:

\section{Pembukaan Tanah}

Pembukaan tanah yang dimaksud dalam hal ini adalah pengupasan tanah dan perintisan jalan.

a. Pengupasan Tanah

Setelah dilakukan eksplorasi dan telah ditentukan lokasi penambangan maka hal yang selanjutnya dilakukan adalah membersihkan lahan tersebut dari segala sesuatu yang berada di permukaan lahan tersebut (vegetasi atau bahkan pemukiman penduduk). Pekerjaan ini sering disebut dengan land clearing.

b. Vegetasi

Dilakukan pembersihan dan pembabatan (semak-semak), pohon-pohon besar/kecil dan batuan yang menghalangi pekerjaan selanjutnya. Pada PT. Pamapersada Nusantara jobsite PT. Adaro Indonesia, alat yang digunakan untuk land clearing ini adalah bulldozer D85.

c. Penggalian Tanah Penutup dan Batubara

Dalam melakukan kegiatan pemberaian material lapisan penutup, PT. Pamapersada Nusantara jobsite PT. Adaro Indonesia menggunakan metode peledakan (blasting), yang kemudian digali menggunakan alat gali muat dan langsung diangkut menggunakan alat angkut. Metode yang digunakan yaitu dengan peledakan (blasting), hal ini digunakan karena untuk mempermudah dan mempercepat proses produksi. Kemudian material lapisan penutup tersebut diangkut ke area penimbunan (disposal). 
d. Penimbunan Lapisan Penutup

Seperti yang sudah dijelaskan diatas, top soil merupakan lapisan tanah penutup yang paling atas. Lapisan tanah ini memiliki kandungan unsur hara (seperti humus) yang cukup tinggi yang memungkinkan tumbuh dan berkembangnya vegetasi. Oleh karena itu, pada tahap penimbunan (dumping), jenis tanah ini dipisahkan dari yang lain (overburden dan interburden) karena pada penutupan tambang, tanah ini dipergunakan pada tahap reklamasi.

Pada tahap penimbunan ini adapun halhal yang harus diperhatikan yaitu:

1) Lokasi Penimbunan

Tidak terlalu jauh dari lokasi hauling karena hal ini mempengaruhi cycle time alat yang kemudian berpengaruh pada produktivitas.

2) Kestabilan Timbunan (ketinggian dan kemiringan)

Material yang ditimbun merupakan material loose dengan void yang besar, agar tidak terjadi amblasan maupun longsoran maka ketinggian dan kemiringan harus dibuat dengan berdasarkan dimensi yang sesuai dengan karakteristik geoteknik material setempat. Untuk itu dimungkinkan pula dilakukan perataan dan pemadatan dengan alat-alat khusus

\section{ANALISA DAN PERHITUNGAN}

\section{Waktu Siklus pada Aktivitas Dozing}

Waktu Siklus $=$ Dozing time + Reversing time $=15,3$ detik $+10,2$ detiK $=25,5$ DETIK

\section{Faktor yang Mempengaruhi Produktivitas}

\section{Dozer}

\section{Blade Capacity (Ukuran Blade)}

Untuk penelitian di PT. Pamapersada Nusantara dozer yang digunakan yaitu komatsu D155A dengan tipe blade sigmadozer dengan kapasitas 9,4 $\mathrm{m}^{3}$.

2. Swell Factor

Sweel Factor $=($ volome $\quad(B C M)) /($ volume (LCM)).....4.1

$=1 / 1,11$

$=0,9 \mathrm{Bcm} / \mathrm{Lcm}$

\section{Grade Factor (faktor kelandaian)}

4. Efisiensi Kerja

Berikut perhitungan efisiensi kerja aktual dilapangan di dapat hasil sebagai berikut: a. Perhitungan Efisiensi pada tanggal 07 Maret 2017

Efisiensi $=\mathrm{CT} /(\mathrm{CT}+\mathrm{DT}) \times 100 \%$.

$$
\begin{aligned}
& =24,2 /(24,2+8,3) \times 100 \% \\
& =74 \%
\end{aligned}
$$

Perhitungan Efisiensi pada tanggal 08 Maret 2017

$$
\begin{aligned}
\text { Efisiensi } & =\mathrm{CT} /(\mathrm{CT}+\mathrm{DT}) \times 100 \% \\
& =22,8 /(22,8+7,9) \times 100 \% \\
& =74 \%
\end{aligned}
$$

\section{Produktivitas Alat}

$Q=q \times 60 / C m \times e \times E$

Keterangan:

$$
\begin{array}{ll}
\mathrm{Q} & =\text { Produksi }(\mathrm{BCM} / \mathrm{jam}) \\
\mathrm{q} & =\text { Kapasitas blade } \times \text { Faktor blade } \\
\mathrm{Cm} & =\text { Cycle time } \\
\mathrm{e} & =\text { Faktor kelandaian (grade factor) } \\
\mathrm{E} & =\text { Efesiensi kerja }
\end{array}
$$

(Sumber : Specification and Application Handbook (Komatsu), edition 30).

\section{Perhitungan Produktivitas}

Hasil dari data yang di peroleh dari pengamatan di lapangan, dan hasil perhitungan produktivitas sebagai berikut:

Perhitungan produktivitas pada tgl 07 Maret 2017 jam 14:15-15:15

Produksi Persiklus (q)

$\mathrm{q}=$ kapasitas blade $(\mathrm{q} 1) \times$ blade fill factor $(\mathrm{a})$ (tabel 4.2)

$$
=9,4 \mathrm{~m}^{3} \times 0,9=8,46 \mathrm{~m}^{3}
$$

a. Waktu Siklus (cycle time) : 24,2 detik,

b. Grade Factor : :1

c. Efisiensi : :74\%

d. Swell Factor : : $\quad: 9$

Maka:

$$
\begin{aligned}
\mathrm{Q}= & \mathrm{q} \times 60 / \mathrm{Cm} \times \mathrm{e} \times \mathrm{E} \\
= & 8,46 \times(3600 \text { detik }) /(24,2 \text { detik }) \times 1 \times \\
& 0,74 \\
= & 8,46 \times 148,76 \times 0,74 \\
= & 931,29 \mathrm{Lcm} / \mathrm{jam} \times 0,9 \\
= & 838,16 \mathrm{Bcm} / \mathrm{jam}
\end{aligned}
$$

2. Perhitungan produktivitas pada tanggal 08 Maret 2017 jam 08:30-09:30

a. Produksi Persiklus (q)

$q=$ kapasitas blade $(q 1) \times$ blade fill factor

(a) (tabel 4.2)

$=9,4 \mathrm{~m} 3 \times 0,9=8,46 \mathrm{~m} 3$

Waktu Siklus (cycle time) : 22,8 detik

b. Grade Factor : 1

c. Efisiensi : :74\%

d. Swell Factor : : 0,9

Maka:

$$
\begin{aligned}
Q= & q \times 60 / C m \times e \times E \\
= & 8,46 \times(3600 \text { detik }) /(22,8 \text { detik }) \times 1 \times \\
& 0,74 \\
= & 8,46 \times 157,89 \times 0,74
\end{aligned}
$$


$=988,45 \mathrm{Lcm} / \mathrm{jam} \times 0,9$

$=889,60 \mathrm{Bcm} / \mathrm{jam}$

\section{Ketercapaian Target}

Target PT. Pamapersada Nusantara dalam aktivitas dozing di disposal yaitu 1200 $\mathrm{Bcm} / \mathrm{jam}$, yang pada dua kali pengamatan didapat ketercapaian target dengan perhitungan sebagai berikut :

1. Ketercapaian target pada tanggal 07 Maret 2017 jam 14:15-15:15

Ketercapaian $=($ Produktivias Aktual $) /($ Target Produktivitas $) \times 100 \% . \quad=\quad(838,16$ $\mathrm{bcm}) /(1200 \mathrm{bcm}) \times 100 \%=69 \%$

2. Ketercapaian target pada tanggal 08 Maret 2017 jam 08:30-09:30

Ketercapaian $=($ Produktivias Aktual $) /($ Target

Produktivitas) $\times 100 \%$

$(889,60 \mathrm{bcm}) /(1200 \mathrm{bcm}) \times 100 \%=74 \%$

\section{E. PENUTUP}

\section{Kesimpulan}

Dari hasil pengamatan aktivitas dozing di disposal PT. Pamapersada Nusantara, maka dapat disimpulkan :

1. Produktivitas alat gusur bulldozer D155A komatsu di lokasi disposal HW (high wall) tidak ada yang mencapai target 1200 bcm/jam.

2. Produktiviftas pada tanggal 07 Maret 2017, jam 14:15-15:15 yaitu 838,16 bcm/jam dan pada tanggal 08 Maret 2017, jam 08:3009:30 yaitu $889,60 \mathrm{bcm} / \mathrm{jam}$.

3. Ketercapaian target $69 \%$ pada tanggal 07 Maret 2017, dan 74\% pada tanggal 08 Maret 2017.

\section{Saran}

Dari pengamatan yang dilakukan maka kendala yang mempengaruhi produktivitas alat gusur bulldozer D155A komatsu adalah menyamakan rasio material yang masuk, misal $1: 1$ yaitu satu fleet material kering (hasil blasting) dan satu fleet material basah (material cut back dan spoil), agar waktu siklus rendah untuk dapat mengejar target produktivitas

\section{F. DAFTAR PUSTAKA}

1. Indonesianto, Yanto. 2015. Pemindahan Tanah Mekanis. Teknik Pertambangan, Fakultas Teknologi Mineral. Universitas Pembangunan Nasional "Veteran" Yogyakarta. Yogyakarta.

2. Rostiyanti, Susy Fatena. 2008. Alat Berat Untuk Proyek Konstruksi, edisi kedua, Penerbit Rineka Cipta, Jakarta.

3. Anonim, 2001. Spesification \& Application Handbook, 22th Edition. Komatsu. Japan.
4. Anonim, 2007. Spesification \& Application Handbook, 30th Edition. Komatsu. Japan.

5. Anonim. 2017 . Engineering Department. PT. Pamapersada Nusantara district Adaro Indonesia. Kalimantan Selatan. Tidak dipublikasikan. 